\title{
A Brief Survey of Public Knowledge and Stigma Towards Depression
}

\author{
Shoji Yokoya ${ }^{\mathrm{a}, \mathrm{c}}$, Takami Maeno ${ }^{\mathrm{b}}$, Naoto Sakamoto ${ }^{\mathrm{b}}$, Ryohei Goto ${ }^{\mathrm{b}}$, \\ Tetsuhiro Maeno ${ }^{\mathrm{b}}$
}

\begin{abstract}
Background: The burden from depression is affected by the public's beliefs, stigma, and resulting behavior. Lack of knowledge, misunderstanding, and stigma about depressed people and their surroundings are barriers to improving their mental health. This study aimed to examine public beliefs regarding depression, especially how to recognize depression, treatment, and stigma.

Methods: A self-administered questionnaire was distributed to participants receiving an annual health checkup. We asked whether they agreed with four short sentences: "it is not necessary to worry about depression in a person behaving brightly" (misunderstanding about the behavior of depressed people), "rest is important for treating depression" (belief about the necessity of rest), "medicine is effective for treating depression" (belief about the effectiveness of pharmacotherapy) and "a weak personality causes depression" (stigma about the cause of depression). We also analyzed the association between these beliefs and factors such as health literacy, regularly visiting an outpatient clinic, history of depression, and demographic variables.
\end{abstract}

Results: Among 1,085 respondents (75.0\% response rate), 54.5\%, $75.6 \%, 58.9 \%$, and $70.8 \%$ responded appropriately to the "misunderstanding about the behavior of depressed people", "necessity of rest", "effectiveness of pharmacotherapy", and "stigma about the cause of depression" items, respectively. Regarding stigma about the cause of depression, $30.7 \%$ of respondents agreed that a weak personality caused depression. Female sex and younger age group were associated with appropriate answers. Health literacy was only associated with appropriate beliefs about the effectiveness of pharmacotherapy.

Conclusions: Thirty percent of participants had the stigmatizing belief that a weak personality causes depression and only $58.9 \%$ believed in the effectiveness of pharmacotherapy for depression. Over $70 \%$ understood the necessity of rest and knew that depression is pos-

Manuscript submitted November 26, 2017, accepted December 27, 2017

${ }^{a}$ Community-Based Medicine Education Station Kitaibaraki, Faculty of Medicine, University of Tsukuba, Tsukuba, Ibaraki, Japan

${ }^{b}$ Department of Primary Care and Medical Education, Faculty of Medicine, University of Tsukuba, Tsukuba, Ibaraki, Japan

${ }^{\mathrm{c} C}$ Corresponding Author: Shoji Yokoya, Community-Based Medicine Education Station Kitaibaraki, Faculty of Medicine, University of Tsukuba, 1-1-1 Tennoudai, Tsukuba, Ibaraki 305-8575, Japan. Email: s-yokoya@umin.ac.jp

doi: https://doi.org/10.14740/jocmr3282w sible in those who act brighter. General health literacy alone might not improve knowledge and beliefs about depression. An educational intervention or campaign to reduce stigma toward depression and improve knowledge about the treatment of depression is needed.

Keywords: Depression; Mental health; Help-seeking behavior; Medication adherence; Health knowledge; Social stigma; Health literacy; Cross-sectional studies; Surveys and questionnaires

\section{Introduction}

Depression is a highly prevalent mental illness $[1,2]$. It is a major cause of disability worldwide [3]. In order to minimize disability due to depression, it is necessary for people with depression to receive treatment earlier and in an uninterrupted manner, and return to their social activities.

Not all people with depression receive treatment during the early stages. According to a previous study in Japan, $46 \%$ of mental health service recipients obtained services 4 weeks or more after when they thought they needed help. Of the people who did not seek mental health care despite needing it, $28 \%$ had continued awareness of a need to consult a professional for 4 weeks or more [4]. A previous study showed that the main barrier to initiation and continuation of treatment among individuals with common mental disorders was the desire to handle the problem on one's own [5]. Therefore, it is important that people around individuals with depression notice changes and encourage them to consult a doctor.

Treatment for acute depression mainly consists of rest and pharmacotherapy. Resting without stressors is recommended during the acute phase of moderate to severe depression. Nevertheless, according to a previous study across eight countries, $23-67 \%$ of depressed employees continued to work without taking leave. Continuing to work among depressed employees decreases productivity and costs more than absence from work [6].

The effectiveness of antidepressants to treat moderate or severe depression has been established [7-9]. Discontinuation of pharmacotherapy has been associated with worse outcomes [10] and increases the risk of relapse [11]. However, in one 2003 - 2005 survey in the United States, $51 \%$ of patients were adherent to treatment through the first 16 weeks [12]. In a previous study, patient concerns about antidepressants were one of the major predictors of antidepressant discontinuation [13].

In order for people with depression to return to work, it is 
necessary for people around them to have an accurate understanding of depression and provide support [14]. Inadequate understanding by others may interfere with the patient's rest, which is necessary during the acute phase of depression, and may exacerbate the patient's adherence to outpatient visits and medications during the convalescent phase.

Inadequate understanding of depression includes lack of knowledge and stigma. Stigma has two major dimensions: public stigma and self-stigma. Public stigma comprises prejudice, stereotypical beliefs, and discriminatory behavior towards the stigmatized person. Self-stigma is the internalization of these experiences by the stigmatized individual [15]. Previous studies have suggested that public stigma of depression might increase suicide rates [16] and decrease rates of antidepressant use [17]. Self-stigma may inhibit individuals with a mental health disorder from seeking help [18], interfere with treatment adherence [19], and provide barriers to their successful reintegration into society [20].

To improve mental health, it is necessary to lower various barriers such as lack of knowledge, misunderstanding, and stigma. We aimed to examine public beliefs about depression, especially knowledge about how to recognize depression, treatment for depression, and stigma. We also sought to evaluate factors related to these topics.

\section{Materials and Methods}

\section{Participants}

Participants were citizens aged 18 and over receiving annual health checkups provided by the city of Kamisu, located 100 $\mathrm{km}$ east of Tokyo. As of August 2012, the population of Kamisu was 94,633, and 17.7\% were aged 65 and older in 2012. Thus, Kamisu was a small city in terms of population size. The annual health checkup provided by the city of Kamisu is targeted to citizens over the age of 16 years, excluding employed individuals. The checkup rate of the 40- to 74-year-old age group was $33.0 \%$ in 2011 .

\section{Design}

This study was conducted as part of a cross-sectional survey of health literacy and knowledge regarding common diseases. Over 21 days in August and September 2012, a selfadministered questionnaire was distributed to participants at four health checkup sites and collected on the spot. Responses were voluntary and anonymous. Participants were provided with a full explanation of the study's objectives by a trained researcher before written informed consent was sought. The institutional review board of the Faculty of Medicine at the University of Tsukuba approved the study protocol.

\section{Questionnaire}

The questionnaires examined each participant's beliefs regard- ing depression, health literacy, medical condition, and demographic information such as age, sex, and occupational and educational background.

Beliefs regarding depression were evaluated for knowledge on how to recognize depression, knowledge about treatment, and stigma. In consideration of the feasibility of a questionnaire survey targeting citizens, we avoided exhaustive questions on beliefs about depression. We decided to show four short sentences and ask participants whether they agreed with each sentence or not. These four sentences were developed by the study's authors and several professionals related to primary care, based on a literature review $[12,13,18,19,21$, 22]. These four items selected as basic knowledge and stigma which should be understood correctly by the public not to interfere with treatment of people with depression and their reintegration into society.

The first item concerned a common misunderstanding about how to recognize depression, expressed in the following sentence: "it is not necessary to worry about depression in a person behaving brightly" (misunderstanding about the behavior of depressed people). Some depressed persons hide their distress and might smile in public, which makes it difficult for others to notice that they are depressed. People might believe that persons with depression do not laugh. In patients with depression, although "laughter of pleasure" is reduced, "smile as a social signature" remains [23]. It is said that the Japanese believe strongly that they must behave in a favorable manner in public. Therefore, we thought that it would be appropriate to use this item to identify this misunderstanding.

The second and third items were about knowledge about the basic treatment for depression: "rest is important for treating depression" (belief about the necessity of rest) and "medicine is effective for treating depression" (belief about the effectiveness of pharmacotherapy).

The fourth item was about stigma towards depression: "a weak personality causes depression" (stigma about the cause of depression). Belief that a weak personality, as opposed to biological factors, is the cause of depression is a major source of stigma towards depression in Japan [22, 24, 25].

Possible answers for each item were strongly agree, agree, disagree, strongly disagree, and uncertain.

Health literacy and health conditions were examined as related factors. Health literacy includes the cognitive and social skills that determine the motivation and ability of individuals to gain access to, understand, and use information in ways that promote and maintain good health [26]. Nutbeam classified health literacy into three types of literacy: basic/functional literacy, communicative/interactive literacy, and critical literacy [27]. Health literacy was evaluated using the communicative and critical health literacy scale [28], a five-item, two-domain questionnaire. The two domains include communicative health literacy (items 1 - 3) and critical health literacy (items 4 - 5). These items asked whether the participant would be able to 1) collect health-related information from various sources, 2 ) extract the desired information, 3) understand and communicate the obtained information, 4) consider the credibility of the information and 5) make decisions based on the information, specifically in the context of health-related issues. Each item was rated on a five-point scale, with scores ranging from 1 to 
Table 1. Characteristics of Study Participants $(n=1,085)$

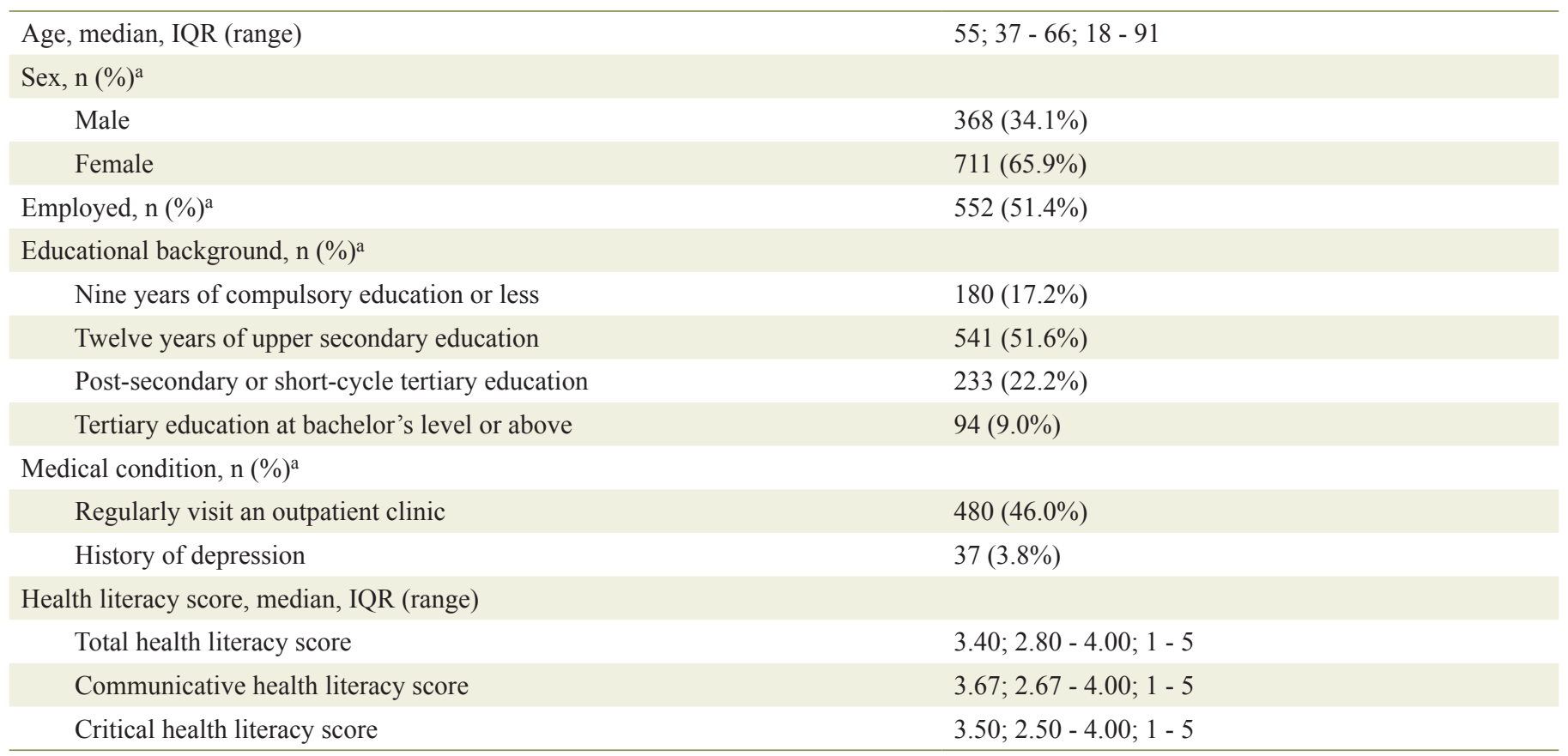

IQR: interquartile range; SD: standard deviation; HL: health literacy. ${ }^{a}$ Missing values were omitted when calculating percentages.

5, with 1 indicating strongly disagree, 2 indicating somewhat disagree, 3 indicating neither agree nor disagree, 4 indicating somewhat agree, and 5 indicating strongly agree. The internal consistency of the five items was adequately high (Cronbach's $\alpha=0.86)$. The item-total correlations were all positive and ranged from 0.77 to 0.85 [28].

Medical conditions included currently making outpatient visits regularly and history of depression.

\section{Statistical analysis}

Subjects with no missing data in the items about beliefs regarding depression, health literacy scores, and age were included in the analysis. Responses of "strongly agree" and "agree" to "necessity of rest" and "effectiveness of pharmacotherapy" were defined as appropriate beliefs, and responses of "strongly disagree" and "disagree" to "misunderstanding about the behavior of depressed people" and "stigma about the cause of depression" were defined as appropriate beliefs. Descriptive statistics were used to characterize participants' demographics and beliefs regarding depression. Age and health literacy score were divided into two groups based on the median value. Univariate analysis was performed to evaluate the associations between appropriate beliefs regarding depression and health literacy scores, health conditions, and demographic data. The Chi-square test was used for categorical variables and Student's $t$-test was used for continuous variables. Multivariate logistic regression analysis with forced entry was performed to examine the association between beliefs regarding depression and all factors that were significantly associated with at least one belief regarding depression in the univariate analysis. The significance level was set at $\mathrm{P}<0.05$. All statistical analyses were performed with IBM SPSS Statistics 24 for Windows (IBM Japan, Tokyo, Japan).

\section{Results}

\section{Subject characteristics}

A total of 1,447 citizens participated in the survey. Replies from 1,085 citizens with no missing data for age, beliefs regarding depression, and health literacy scores were used for analysis. The response rate was $75.0 \%$. The characteristics of the respondents are listed in Table 1. The median age was 55 (interquartile range (IQR), 37 - 66) years. Among all respondents, $711(65.9 \%)$ were female, $480(46.0 \%)$ regularly visited a medical clinic or hospital, and $37(3.8 \%)$ have experienced depression.

\section{Beliefs regarding depression}

Figure 1 shows public beliefs regarding depression. The percentage of participants who responded appropriately to "necessity of rest" and "effectiveness of pharmacotherapy" was $75.6 \%$ and $58.9 \%$, respectively. The percentage of participants who responded appropriately to "misunderstanding about the behavior of depressed people" and "stigma about the cause of depression" was $54.5 \%$ and $70.8 \%$, respectively. Regarding "stigma about the cause of depression," $30.7 \%$ of participants reported that they "strongly agree" or "agree". 


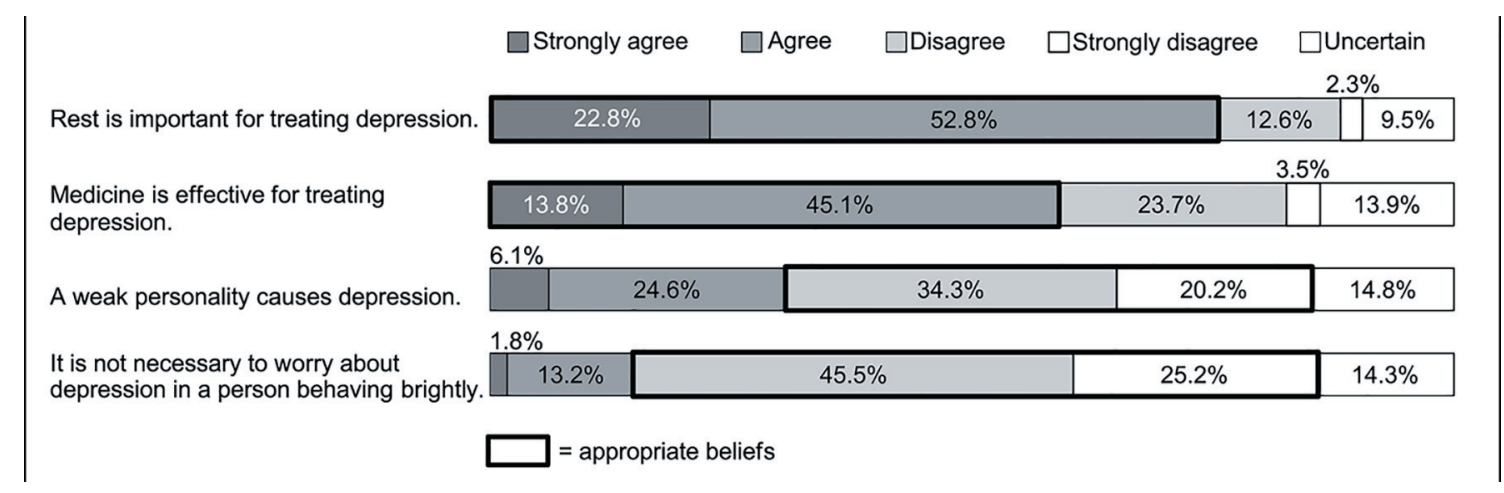

Figure 1. The public's beliefs regarding depression $(n=1,085)$.

\section{Association between beliefs regarding depression and vari- ous factors}

Table 2 shows the results of univariate analysis on the association between beliefs regarding depression and various factors. A higher percentage of participants who responded appropriately to the "misunderstanding about the behavior of depressed people" item were in the younger age group (83.5\% vs. $58.2 \%$; $\mathrm{P}<0.001)$, female $(77.5 \%$ vs. $58.2 \%$; $\mathrm{P}<0.001)$, employed (76.6\% vs. $64.9 \%$; $\mathrm{P}<0.001)$, or have a history of depression $(89.2 \%$ vs. $70.5 \% ; \mathrm{P}=0.01)$. Participants who responded appropriately were less likely to regularly visit an outpatient clinic $(64.0 \%$ vs. $77.8 \%$; $\mathrm{P}<0.001)$. The percentage of participants who responded appropriately differed by educational background $(\mathrm{P}<0.001)$.

A higher percentage of participants who responded appropriately to the sentence about the "belief about necessity of rest" were in the younger age group $(81.1 \%$ vs. $70.1 \%$; $\mathrm{P}<$ $0.001)$ or female $(79.0 \%$ vs. $68.8 \%$; $\mathrm{P}<0.001)$. The percentage of participants who responded appropriately differed by educational background $(\mathrm{P}=0.03)$.

Participants who responded appropriately to the "belief about effectiveness of pharmacotherapy" sentence were more likely to be in the older age group $(62.2 \%$ vs. $55.6 \% ; \mathrm{P}=0.03)$, and unemployed (62.1\% vs. $55.4 \% ; \mathrm{P}=0.03)$.

Participants who responded appropriately to the "stigma about cause of depression" sentence were more likely to be in the younger age group $(65.7 \%$ vs. $43.3 \%$; $\mathrm{P}<0.001)$ and female $(59.5 \%$ vs. $45.1 \%$; $\mathrm{P}<0.001)$. They were less likely to regularly visit an outpatient clinic $(49.6 \%$ vs. $59.5 \%$; $\mathrm{P}=$ $0.001)$. The percentage of them differed by educational background $(\mathrm{P}<0.001)$.

Participants who responded appropriately to "misunderstanding about the behavior of depressed people", "necessity of rest", and "effectiveness of pharmacotherapy" sentences had significantly higher scores on the total health literacy scale.

\section{Factors independently associated with beliefs regarding depression}

Table 3 shows the results of multivariate logistic regression analysis on beliefs regarding depression and total health lit- eracy score, age group, sex, employment status, educational background, regularly visiting an outpatient clinic, and history of depression.

Higher total health literacy score was associated with appropriate responses for "effectiveness of pharmacotherapy" (adjusted odds ratio (OR), 1.48; 95\% confidence interval (CI), 1.14 - 1.93). Female sex was positively associated with appropriate responses for all 4 items; "misunderstanding about the behavior of depressed people" (adjusted OR, 2.25; 95\% CI, 1.64 - 3.10), "necessity of rest" (adjusted OR, 1.58; 95\% CI, 1.14 - 2.18), "effectiveness of pharmacotherapy" (adjusted OR, 1.35; 95\% CI, 1.02 - 1.80), and "stigma about the cause of depression" (adjusted OR, 1.56; 95\% CI, 1.17 - 2.08). Younger age group was positively associated with appropriate responses for "misunderstanding about the behavior of depressed people" (adjusted OR, 2.45; 95\% CI, 1.69 - 3.53), "necessity of rest" (adjusted OR, 1.93; 95\% CI, 1.33 - 2.80), and "stigma about the cause of depression" (adjusted OR, 1.99; 95\% CI, 1.45 - 2.73). Being employed was positively associated with appropriate responses for "misunderstanding about the behavior of depressed people" (adjusted OR, 1.41; 95\% CI, 1.02 1.95 ) and negatively associated with appropriate responses for "necessity of rest" (adjusted OR, 0.68; 95\% CI, 0.49 - 0.95). Higher educational background and history of depression were associated with appropriate responses for "misunderstanding about the behavior of depressed people".

\section{Discussion}

This survey evaluated knowledge and stigma towards depression in a large number of citizens. First, $30.7 \%$ of the participants agreed with the stigma that a weak personality causes depression. The details and degree of stigma associated with mental health disorders vary across cultures and countries [22]. In a 2003 study about the stigma of depression in Japanese versus Australians, $45.4 \%$ of Japanese had the attitude that "problem is a sign of personal weakness" and $40.2 \%$ had the attitude that "problem is not a real medical illness" in response to a person in a vignette about depression, while few Australians had these attitudes (13.4\% and 14.6\%, respectively) [22]. Although direct comparisons could not be performed, in our study conducted 9 years after that study in 2003, the number of people 

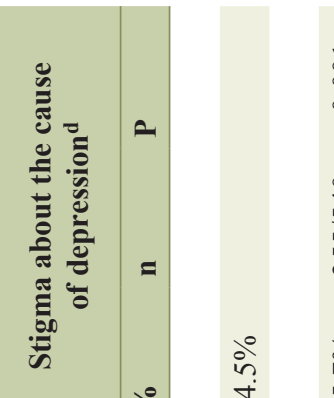

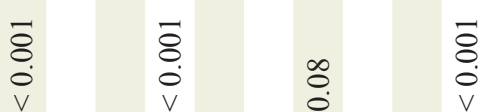

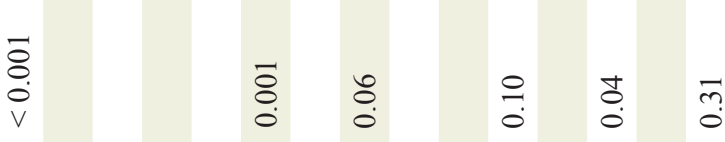

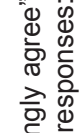

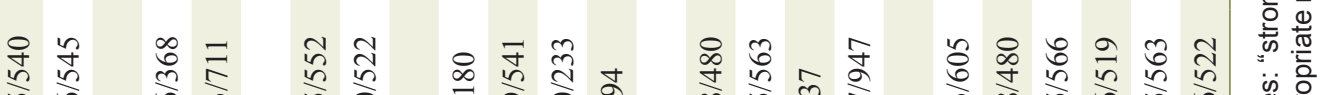

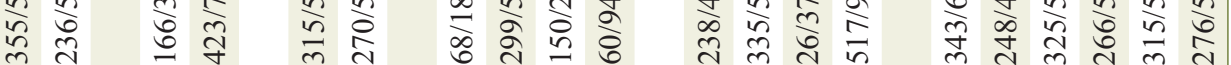

象 遂

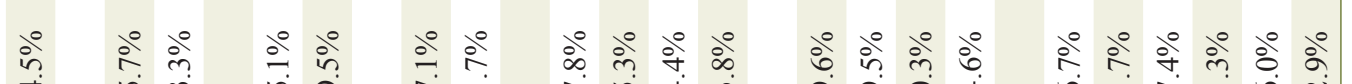

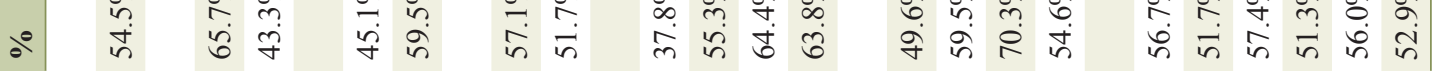

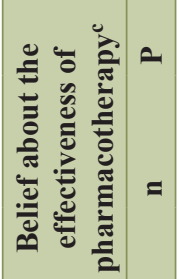

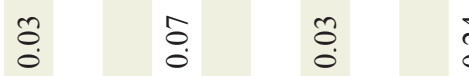

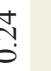

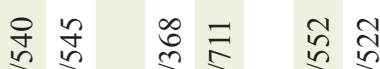

$\stackrel{1}{\mathfrak{0}} \stackrel{0}{0}$

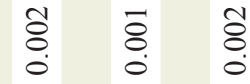

क्ष $=\dot{0}$

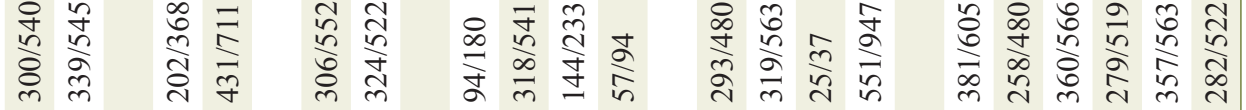

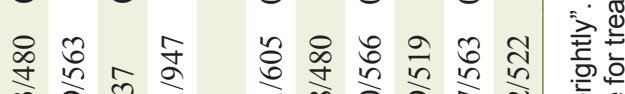

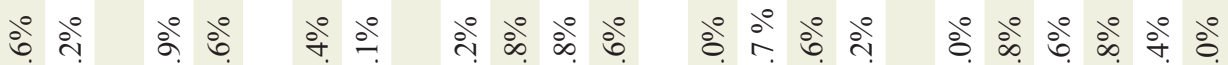

을

$\stackrel{\substack{\circ \\ \infty}}{\stackrel{\infty}{n}}$

के तु में

in तु

तi $\begin{gathered}\infty \\ \text { in }\end{gathered}$

$\overrightarrow{8}$
$\dot{0}$
$v$

官

$\frac{2}{\square}$

ڤ̊.

ণิ

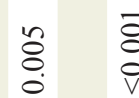

$\stackrel{8}{8}$

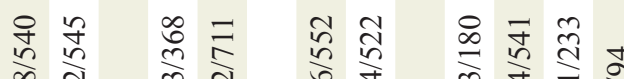

\&

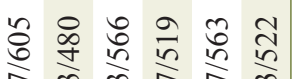

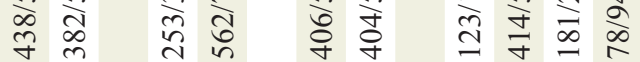

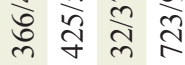

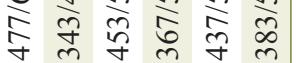

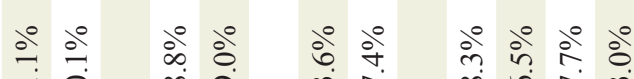

$\theta^{0}$

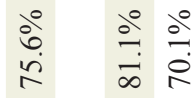

क श

mi

官

$\vec{\Xi}$
$\dot{0}$
$v$

官

$\dot{0} \leqslant \dot{\infty}$

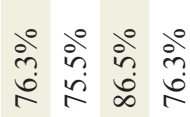

oे

$\stackrel{\infty}{\infty}$

亮皆

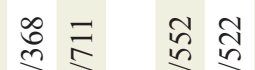

$\overrightarrow{8}$
$\dot{0}$
$\vee$

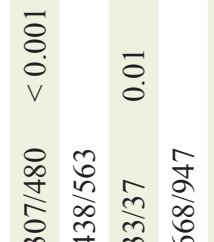

$\begin{array}{llll}0 & 0 & 0 & 0 \\ 0 & 0 & 0 \\ 0 & 0 & 0\end{array}$

要
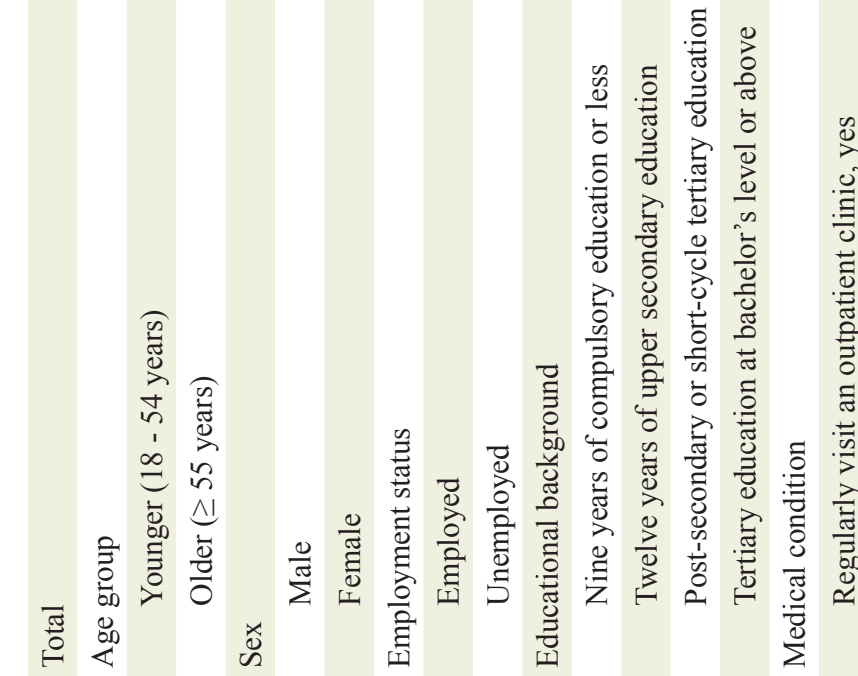

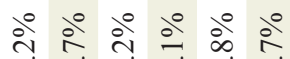
ᄃ

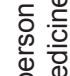

ब.

응 "ญ

훙

芌 "ᄈ⿱亠凶禸

ㅎํㅎำ

은

흥 


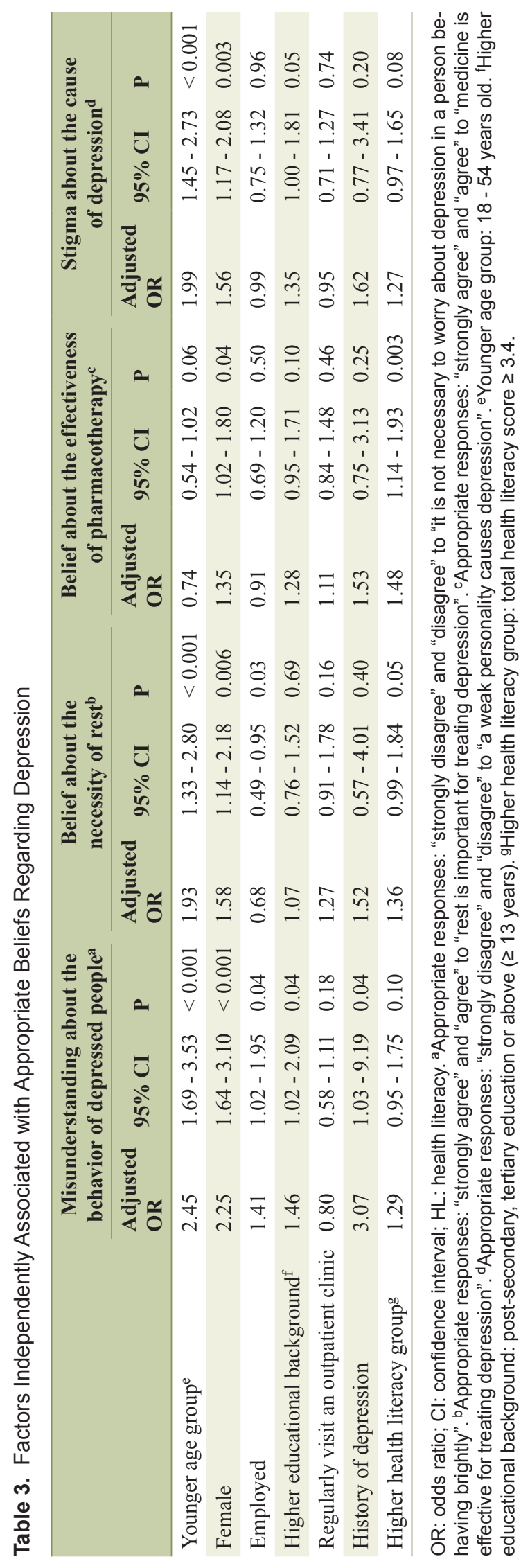

who believe that a weak personality causes depression is likely to have decreased. For the purpose of preventing suicide associated with depression, in 2010 the Japanese government conducted a campaign asking people to consult with a doctor when they have prolonged sleep disturbances. In addition, attempts have been made in recent years to increase public awareness that depression is a treatable disease. However, a much higher percentage of the Japanese public still believe that a weak personality causes depression compared with the general population in the West. This stigma may delay help-seeking behavior in people with depression and interrupt treatment. According to one study conducted across Japan, $68.8 \%$ of the reason for delayed access to help and $25.0 \%$ of the reason for treatment interruption were the wish to handle the problem on one's own [4]. In other words, the perception that depression is a treatable disease may be lacking in Japan. Furthermore, understanding among the surrounding people is important for depression care; thus, it is necessary to plan an intervention program to reduce public stigma towards depression.

Second, only $58.9 \%$ of respondents expressed a belief in the effectiveness of pharmacotherapy for depression. Not believing in the effectiveness of antidepressants may affect adherence to pharmacotherapy. In a previous Japanese study, approximately $35 \%$ of the public believed in effectiveness of antidepressants [29, 30], which was a smaller proportion than we found in the current study. The reason for this difference may be the difference in how the question was presented between the studies. The previous study asked about people described in a vignette about depression, whereas our study asked about a case specified as depression. However, in an Australian study based on a vignette, $61.4 \%$ of the public rated antidepressants as helpful for treating depression [31]. Recognition of the effectiveness of antidepressants has not spread to the public in Japan, suggesting that public awareness-raising activities on treatment methods are necessary.

Several other findings are described below. Among the public, $75.6 \%$ understood the necessity of rest and $70.8 \%$ knew that depression is possible in those who act brightly; it seemed that public understanding was advanced in these respects. Japanese government statistics show that the number of people diagnosed with depression in recent years has increased greatly. This increase in the number of opportunities to be in contact with people diagnosed with depression may be one reason for increased understanding. In addition, respondents may have understood the character of people who try to avoid behaviors that make others uncomfortable. However, according to a 2003 survey, the Japanese public recognized that people with depression have a mental health problem, but tended not to recognize that it was a disease named depression [29]. Even knowing that observing a person's behavior cannot rule out depression is not enough to notice depression in that person. Further research is required to understand reasons why Japanese people are unlikely to notice depression in other people.

In multivariate analysis, health literacy was associated only with an appropriate belief about the effectiveness of pharmacotherapy. Health literacy examined in this study consisted of the ability to collect information and critically examine it. Health literacy plays a role in successful self-management of chronic disease [32]. However, general health literacy alone 
might not be sufficient to improve mental health literacy. One reason is that mental health literacy may be affected by culture. Even among countries with high education standards, there is a large difference in beliefs about the causes of mental illness, attitudes about seeking help [22, 33, 34].

For all four beliefs, a higher proportion of women than men had appropriate responses. The association between knowledge and sex did not reach statistical significance in previous studies $[35,36]$. A previous study of Japanese high school students also showed that females were less likely to stigmatize depression as a sign of personal weakness [25]. However, in a review about stigma towards mental disorders, there were no clear associations between stigma and sex [37, 38]. Regarding knowledge and stigma about depression, it is difficult to state a universal relationship based on sex, because the associations between sex and social situations are complex and vary from region to region. Young people, with the exception of beliefs about the efficacy of pharmacotherapy, were more likely to have appropriate beliefs in three categories. This result is consistent with the results of previous studies showing that younger adults have more appropriate knowledge and attitudes towards depression and mental illness [39, 40]. A history of depression was significantly associated with appropriate response only to the "misunderstanding about the behavior of depressed people" item. Although not significant in the other three beliefs, there was a possibility that the analysis was underpowered because there were only a few participants with a history of depression. Being employed and higher educational background were associated with some beliefs, but the strength of the associations was low.

This study had several limitations. First, because we attempted to narrow down the questions, an exhaustive survey of beliefs about depression was not made. However, we carefully selected survey items that were supposed to be important for each step necessary to minimize disability due to depression. Second, questions explicitly named the disease as depression; therefore, it was unknown whether the respondents understood how depression is diagnosed. Regardless of the ability to identify depression, public beliefs about depression could be investigated. Third, this survey was targeted at people receiving an annual health checkup; therefore, there is a possibility that they had more awareness of health issues. Fourth, this survey was conducted in a limited geographic area; therefore, it was hard to generalize it to the entire Japanese population.

In conclusion, $30 \%$ of participants had the stigmatizing belief that a weak personality causes depression. Approximately $60 \%$ of participants believed in the effectiveness of pharmacotherapy for depression. Although general health literacy was associated with beliefs about the effectiveness of pharmacotherapy, this alone might not improve knowledge and reduce stigma about depression. An educational intervention or campaign to reduce stigma toward depression and improve knowledge about treatment of depression is needed.

\section{Grant Support}

This study was supported by a Japan Society for the Promotion of Science KAKENHI grant (JP 22659129).

\section{Conflict of Interest}

The authors have no conflict of interest to disclose with respect to this study.

\section{References}

1. Kessler RC, Chiu WT, Demler O, Merikangas KR, Walters EE. Prevalence, severity, and comorbidity of 12-month DSM-IV disorders in the National Comorbidity Survey Replication. Arch Gen Psychiatry. 2005;62(6):617-627.

2. Inagaki M, Ohtsuki T, Yonemoto N, Oikawa Y, Kurosawa M, Muramatsu K, Furukawa TA, et al. Prevalence of depression among outpatients visiting a general internal medicine polyclinic in rural Japan. Gen Hosp Psychiatry. 2013;35(3):286-290.

3. GBD 2016 Disease and Injury Incidence and Prevalence Collaborators. Global, regional, and national incidence, prevalence, and years lived with disability for 328 diseases and injuries for 195 countries, 1990-2016: a systematic analysis for the Global Burden of Disease Study 2016. Lancet. 2017;390(10100):1211-1259.

4. Kanehara A, Umeda M, Kawakami N. Barriers to mental health care in Japan: Results from the World Mental Health Japan Survey. Psychiatry Clin Neurosci. 2015;69(9):523-533.

5. Mojtabai R, Olfson M, Sampson NA, Jin R, Druss B, Wang PS, Wells KB, et al. Barriers to mental health treatment: results from the National Comorbidity Survey Replication. Psychol Med. 2011;41(8):1751-1761.

6. Evans-Lacko S, Knapp M. Global patterns of workplace productivity for people with depression: absenteeism and presenteeism costs across eight diverse countries. Soc Psychiatry Psychiatr Epidemiol. 2016;51(11):1525-1537.

7. Arroll B, Elley CR, Fishman T, Goodyear-Smith FA, Kenealy T, Blashki G, Kerse N, et al. Antidepressants versus placebo for depression in primary care. Cochrane Database Syst Rev. 2009;(3):CD007954.

8. Papakostas GI, Perlis RH, Scalia MJ, Petersen TJ, Fava M. A meta-analysis of early sustained response rates between antidepressants and placebo for the treatment of major depressive disorder. J Clin Psychopharmacol. 2006;26(1):56-60.

9. Papakostas GI. Antidepressants and their effect on cognition in major depressive disorder. J Clin Psychiatry. 2015;76(8):e1046.

10. Melartin TK, Rytsala HJ, Leskela US, Lestela-Mielonen PS, Sokero TP, Isometsa ET. Continuity is the main challenge in treating major depressive disorder in psychiatric care. J Clin Psychiatry. 2005;66(2):220-227.

11. Papakostas GI, Perlis RH, Seifert C, Fava M. Antidepressant dose reduction and the risk of relapse in major depressive disorder. Psychother Psychosom. 2007;76(5):266270.

12. Akincigil A, Bowblis JR, Levin C, Walkup JT, Jan S, 
Crystal S. Adherence to antidepressant treatment among privately insured patients diagnosed with depression. Med Care. 2007;45(4):363-369.

13. Hunot VM, Horne R, Leese MN, Churchill RC. A cohort study of adherence to antidepressants in primary care: the influence of antidepressant concerns and treatment preferences. Prim Care Companion J Clin Psychiatry. 2007;9(2):91-99.

14. de Vries G, Koeter MW, Nabitz U, Hees HL, Schene AH. Return to work after sick leave due to depression; a conceptual analysis based on perspectives of patients, supervisors and occupational physicians. J Affect Disord. 2012;136(3):1017-1026.

15. Wood L, Birtel M, Alsawy S, Pyle M, Morrison A. Public perceptions of stigma towards people with schizophrenia, depression, and anxiety. Psychiatry Res. 2014;220(12):604-608

16. Schomerus G, Evans-Lacko S, Rusch N, Mojtabai R, Angermeyer MC, Thornicroft G. Collective levels of stigma and national suicide rates in 25 European countries. Epidemiol Psychiatr Sci. 2015;24(2):166-171.

17. Lewer D, O’Reilly C, Mojtabai R, Evans-Lacko S. Antidepressant use in 27 European countries: associations with sociodemographic, cultural and economic factors. Br J Psychiatry. 2015;207(3):221-226.

18. Corrigan P. How stigma interferes with mental health care. Am Psychol. 2004;59(7):614-625.

19. Sirey JA, Bruce ML, Alexopoulos GS, Perlick DA, Raue P, Friedman SJ, Meyers BS. Perceived stigma as a predictor of treatment discontinuation in young and older outpatients with depression. Am J Psychiatry. 2001;158(3):479481.

20. Corrigan PW, Edwards AB, Green A, Diwan SL, Penn DL. Prejudice, social distance, and familiarity with mental illness. Schizophr Bull. 2001;27(2):219-225.

21. Hess SG, Cox TS, Gonzales LC, Kastelic EA, Mink SP, Rose LE, Swartz KL. A survey of adolescents' knowledge about depression. Archives of psychiatric nursing. 2004;18(6):228-234.

22. Griffiths KM, Nakane Y, Christensen H, Yoshioka K, Jorm AF, Nakane H. Stigma in response to mental disorders: a comparison of Australia and Japan. BMC Psychiatry. 2006;6:21.

23. Sakamoto $S$, Nameta $K$, Kawasaki $T$, Yamashita $K$, Shimizu A. Polygraphic evaluation of laughing and smiling in schizophrenic and depressive patients. Percept Mot Skills. 1997;85(3 Pt 2):1291-1302.

24. Ando S, Yamaguchi S, Aoki Y, Thornicroft G. Review of mental-health-related stigma in Japan. Psychiatry Clin Neurosci. 2013;67(7):471-482.

25. Yoshioka K, Reavley NJ, MacKinnon AJ, Jorm AF. Stigmatising attitudes towards people with mental disorders: results from a survey of Japanese high school students. Psychiatry Res. 2014;215(1):229-236.

26. Nutbeam D. Health promotion glossary. Health Promot Int. 1998;13(4):349-364.
27. Nutbeam D. Health literacy as a public health goal: a challenge for contemporary health education and communication strategies into the 21 st century. Health Promot Int. 2000;15(3):259-267.

28. Ishikawa H, Nomura K, Sato M, Yano E. Developing a measure of communicative and critical health literacy: a pilot study of Japanese office workers. Health Promot Int. 2008;23(3):269-274.

29. Jorm AF, Nakane Y, Christensen H, Yoshioka K, Griffiths KM, Wata Y. Public beliefs about treatment and outcome of mental disorders: a comparison of Australia and Japan. BMC Med. 2005;3:12.

30. Okuyama T, Nakane Y, Endo C, Seto T, Kato M, Seki N, Akechi T, et al. Mental health literacy in Japanese cancer patients: ability to recognize depression and preferences of treatments-comparison with Japanese lay public. Psychooncology. 2007;16(9):834-842.

31. Morgan AJ, Reavley NJ, Jorm AF. Beliefs about mental disorder treatment and prognosis: comparison of health professionals with the Australian public. Aust N Z J Psychiatry. 2014;48(5):442-451.

32. Heijmans M, Waverijn G, Rademakers J, van der Vaart R, Rijken M. Functional, communicative and critical health literacy of chronic disease patients and their importance for self-management. Patient Educ Couns. 2015;98(1):4148.

33. Altweck L, Marshall TC, Ferenczi N, Lefringhausen K. Mental health literacy: a cross-cultural approach to knowledge and beliefs about depression, schizophrenia and generalized anxiety disorder. Front Psychol. 2015;6:1272.

34. Na S, Ryder AG, Kirmayer LJ. Toward a Culturally Responsive Model of Mental Health Literacy: Facilitating Help-Seeking Among East Asian Immigrants to North America. Am J Community Psychol. 2016;58(1-2):211225.

35. Bener A, Ghuloum S. Gender differences in the knowledge, attitude and practice towards mental health illness in a rapidly developing Arab society. Int J Soc Psychiatry. 2011;57(5):480-486.

36. Nakayama T, Amagasa T. Special reference to employee knowledge about depression and suicide: baseline results of a workplace-based mental health support program. Psychiatry Clin Neurosci. 2004;58(3):280-284.

37. Jorm AF, Oh E. Desire for social distance from people with mental disorders. Aust N Z J Psychiatry. 2009;43(3):183200.

38. Calear AL, Griffiths KM, Christensen H. Personal and perceived depression stigma in Australian adolescents: magnitude and predictors. J Affect Disord. 2011;129(13):104-108.

39. Fisher LJ, Goldney RD. Differences in community mental health literacy in older and younger Australians. Int J Geriatr Psychiatry. 2003;18(1):33-40.

40. Wang J, He Y, Jiang Q, Cai J, Wang W, Zeng Q, Miao J, et al. Mental health literacy among residents in Shanghai. Shanghai Arch Psychiatry. 2013;25(4):224-235. 